\title{
A Review of the Healthy Mindsets for Super Kids Program
}

\author{
Stephanie Azri, Jennifer Cartmel, and Stephen Larmar \\ School of Human Services and Social Work, Griffith University, Brisbane, Queensland, Australia
}

\begin{abstract}
The notion of resilience has emerged in the 21 st century as an important factor influencing children's responses to adverse events. In the past 10 years, resilience theory and resilience programs for children have flourished globally. 'Healthy Mindsets for Super Kids' is a new program aimed at building resilience in children aged 9-14. The program features 10 modules, illustrated by superhero themes, on topics of communication and social skills, anger management, grief and loss, body image, healthy relationships, and positive thinking. This review will introduce the Healthy Mindsets for Super Kids program (Jessica Kingsley publishers, 2014) in use by practitioners in educational, community and mental health settings. It will describe its content, evaluation and the value in building resilience in children at risk of mental health issues.
\end{abstract}

- Keywords: Healthy Mindsets for Super Kids, Jessica Kingsley Publishers, counselling, child and youth mental health, resilience program, guidance counselling, mental health, preventative program

The notion of resilience has garnered significant attention in the past 10 years and has been identified as an important factor influencing children's responses to adverse events. Throughout this period, resilience theory and resilience programs for children have flourished globally. While the focus on resilience initially centred upon the investigation of resilience of children of mentally ill parents, it continued with other at-risk groups, such as children from low socio-economic backgrounds and those with learning difficulties (Hunter, 2012; Nair, 2012; Werner, 1993). The subsequent study of resilience facilitated a theoretical shift towards strength-based models that emphasised the inclusion of a range of child populations. A range of group-based psychosocial-education and group therapy programs addressing issues of resilience have emerged as efficient tools. This article introduces the 'Healthy Mindsets for Super Kids' program in use by professionals involved with children in educational, community and mental health settings.

ADDRess for CORRESPONDENCE: Stephanie Azri, School of Human Services and Social Work, Logan campus, Griffith University, University Drive, Meadowbrook QLD 4131, Australia. Email: Stephanie.Azri@health.qld.gov.au 


\section{Background}

Fundamentally, resilience provides a framework for understanding the factors that influence how children respond to difficult events in different ways. For the purpose of this article, resilience is defined as one's ability to overcome negative events. However, it is believed that resilience is dependent on various factors, such as personality traits, interactions with friends and family members, environments, and access to resources and skills (Australian Research Alliance for Children and Youth [ARACY], 2012; Hunter, 2012; Leadbeater, Dodgen, \& Solarz, 2005; Masten, Best, \& Garmezy, 1990; Nair, 2012). Inherent to the concept of resilience is the principle that resilience should be regarded as positive and adaptive over time. At an individual level, children's cognitive and psychosocial functioning affects their ability to overcome adverse events.

Additionally, it has been found that children's social skills, self-esteem, access to skills and resources, as well as a sense of belonging, foster resilience skills; that is, the ability to 'bounce back' from negative experiences. In earlier studies of resilience, it was argued that 'special skills' may help children cope with various circumstances (Hunter, 2012; Masten, 1999; Nair, 2012; National Children's Home $[\mathrm{NCH}], 2007)$. These may include individual strategies and support from schools, families and communities. Such skills have been described as resulting in good outcomes, regardless of individual children's status. Further, these skills guide children's ability to cope with stress, recover from traumatic incidents, and prepare for future situations. The skills discussed in the many studies on resilience focus on relationships, trust and assertiveness, as well as on the more complex notions of realistic goal setting, positive self-views, and the ability to manage feelings and impulses. Factors identified by Daniel and Wassell (2002) include having a sense of competence, a sense of control, problem-solving skills, communication skills, empathy, reflective behaviour, independence and social abilities, as well as trust, and access to resources. Furthermore, three protective factors that include personal traits, a strong supportive family, and the positive input of the community including peers and friends, have been highlighted (ARACY, 2012; Werner, 1993).

\section{The Healthy Mindsets for Super Kids program}

The Healthy Mindsets for Super Kids program was initially developed in response to the growing awareness that teachers and parents did not always have the time or opportunity to teach children the necessary life skills to overcome specific challenges in life. The formulation of the program was also influenced by the trend in Allied Health in Australia that prioritises the administration of clinical support for a minority population of at-risk children. While this trend is important to the care of at-risk populations, limited attention is often given to a larger population of children presenting 'routine' issues, who still require additional help in building resilience and acquiring necessary skills of coping. The current gap in practice concerning the idea that resilience should be regarded as a preventative notion further inspired the development of the program under review.

Communication skills, emotional regulation, grief and loss, positive thinking, social skills and self-esteem are commonly taught in clusters throughout schools and counselling groups; however, a preventative program encompassing fundamental 
building blocks of skills that can be taught in a systematic way to all children in routine settings was developed as a potential solution and a preventative measure for regular community populations. These skills are linked to outcomes of building confidence and wellbeing to maximise children's opportunities for healthy, productive and rewarding futures, as described by the Melbourne Declaration on Education Goals for Young Australians (Ministerial Council on Education, Employment, Training and Youth Affairs [MEECTYA], 2008). Healthy Mindsets for Super Kids emerged as an early intervention program to reduce the gap in current practice that emphasises intervention frameworks, which focus on reactive methods of engagement.

Healthy Mindsets for Super Kids is a preventative universal program, published by Jessica Kingsley Publishers, teaching core resilience skills to children from 9-14 years of age. The program is divided into 10 modules:

\section{Self-esteem}

2. Communication skills

3. Positive thinking (part 1)

4. Positive thinking (part 2)

5. Grief and loss

6. Anxiety and stress management

7. Anger management

8. Healthy relationships

9. Peer pressure

10. Healthy minds and healthy bodies.

The program design allows for flexible delivery. For example, facilitators may choose to teach a module over 1 hour or for up to 3 hours. Further, the program contains worksheets and activities that may be adapted to the age group of the children taught. The program comes with an accompanying comic book, which introduces a new character for each skill discovered. Each module, illustrated with its own superhero, contains a lesson, printable worksheets, interactive exercises and a 'hands-on' activity that complements the core skills discussed during the module. The hands-on activity may be craft, art, role-play or other creative segments, such as ice breakers or interactive games. The variety of teaching methods, in conjunction with comic art utilised throughout the whole program, serve to foster engagement for children of varying age groups and learning styles. Modules can be offered separately or as a whole program, depending on the needs of the participants, facilitators or organisations. Each hands-on activity segment comes with detailed instructions, an outline of required materials, and stated objectives that identify the purpose of each activity. Finally, in addition to the worksheets and exercises, each module consists of detailed instructions for facilitators, as well as discussion ideas and a summary of teachings to be distributed to the participants at the end of each module. This is designed to foster the involvement of parents and carers in practising the new skills at home. 


\section{Method}

Two trials of the Healthy Mindsets for Super Kids resilience program were conducted in 2010 and 2011. The first trial occurred in a local community centre and was facilitated by a clinical social worker. The second trial was conducted in a local primary school through the oversight of a trained teacher aide. The program was run over 10-week periods during school terms. Each group consisted of eight to twelve children, of mixed genders and ranging from 9 to 12 years of age. Most children attended the full program, which included the 10 modules. However, three children attended more than one program intake.

A mixed methods approach drawing upon both quantitative and qualitative research tools was utilised to evaluate the resilience program, and included selfadministered questionnaires and short answers/comments. Using these two methodological approaches allowed the researcher to gather statistical information as well as unique and individual perspectives not captured in the self-administered questionnaires. It also served to complement the two types of data collection by approaching the research from a different angle. As stated by Creswell (2009), the mix of research methods allows for a more concise and consistent set of results, which in this instance supported the researcher in explaining particular answers in the participants' feedback. Mixed research was more flexible to administer in the context of the delivery of the programs.

This evaluation has attempted to demonstrate a level of validity and reliability of acceptable standards through various factors. Mixed methodology has been strategically used to improve validity and reliability of the evaluative research (Creswell, 2003; Mukherji \& Albon, 2010). By combining methods that involved surveys and short answers, both of quantitative and qualitative means, triangulation of data was achieved, which was deemed to provide strength to the method used in this research. The data was analysed using visual graphs and statistics for the quantitative aspects of this evaluation, and a summary of statements were recorded to capture the qualitative responses. Children were accepted into the program based on the timing of the receipt of their application. The facilitators attempted to create homogenous groups of mixed age and mixed gender groups of children.

\section{Child Evaluation}

An evaluation of children's experience of the program was initiated through the use of a simple evaluation form at the end of the last module (module 10). The evaluation form consisted of four key questions that are identified below:

1. What did you enjoy the most in the program?

2. What did you enjoy the least in the program?

3. How would you score your experience (1 'bad' to 10 'great')

4. Do you have any other comments about the program?

\section{Parent Evaluation}

An evaluation tool designed to facilitate more in-depth perceptions of parents of children involved in the program was developed. The evaluation measure consisted of six key questions: 
1. What feedback did you receive from your child about the program?

2. Which particular module was beneficial to your child?

3. Is there a particular module that was not well received by your child?

4. Have you noticed a difference in your child's behaviour since the program?

5. How would you score the program (1 'bad' to 10 'great')

6. Do you have any other comments?

\section{Facilitator Evaluation}

To understand the experiences of facilitators involved in the program implementation, the two facilitators were invited to record their impressions about their experiences in teaching each module, including their overarching perceptions about the utility of the program design. This data was captured as 'facilitator' narratives through the use of facilitator journal entries completed at the conclusion of each module and at the end of the program.

\section{Results}

Of the entire population of child $(n=36)$ and parent $(n=22)$ participants who engaged in the Healthy Mindsets for Super Kids program evaluation, a total of 36 children and 14 parents completed the surveys. As mentioned in an earlier section, the two facilitators provided comprehensive feedback about their experiences in running the program, in conjunction with their perceptions about each distinct program module. The following section presents key findings extracted from the various measures developed for the program evaluation.

\section{Child Data}

The first question highlighted children's preferred aspects of the overall program (see Figure 1). Question 2 identified key aspects that children disliked about the program (see Figure 2). It should be noted that over a third of the participants did not answer the question. Question 3 enabled the participants to rate the program overall (see Figure 3).

\section{Parental Data}

The following statements provide an overview of the summary of parents' responses based on the first question of the parent evaluation measure:

My child was keen to attend every week. That was a good sign for him!

I only got positive feedbacks. It sounded like they had fun while learning.

I think for me, it boiled down to how my daughter learnt new strategies to deal with everyday issues both at home and at school, and those were down-to-earth strategies. She actually practised them.

The next question invited parents to list the modules that were well received by their child (see Figure 4.) According to parent responses the following modules were particularly beneficial. 
Stephanie Azri, Jennifer Cartmel, and Stephen Larmar

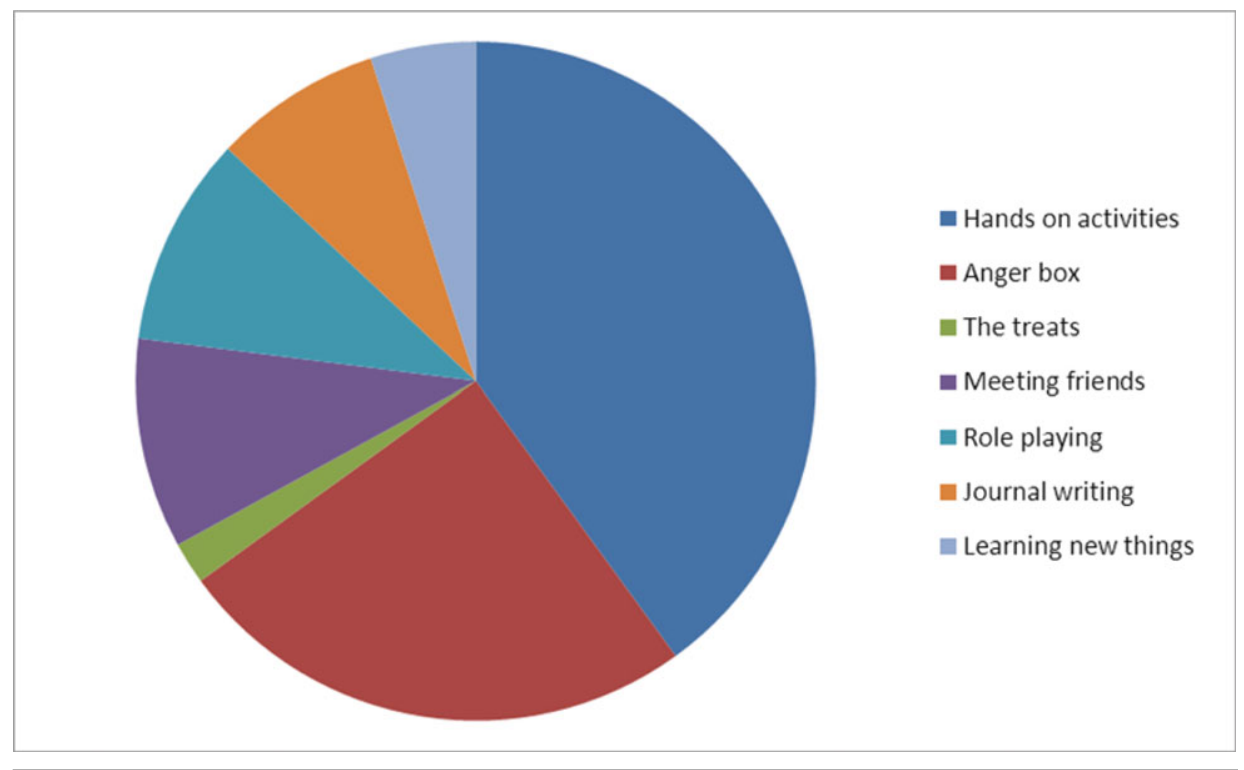

\section{Figure 1}

(Colour online) What did the children enjoy the most about the program?

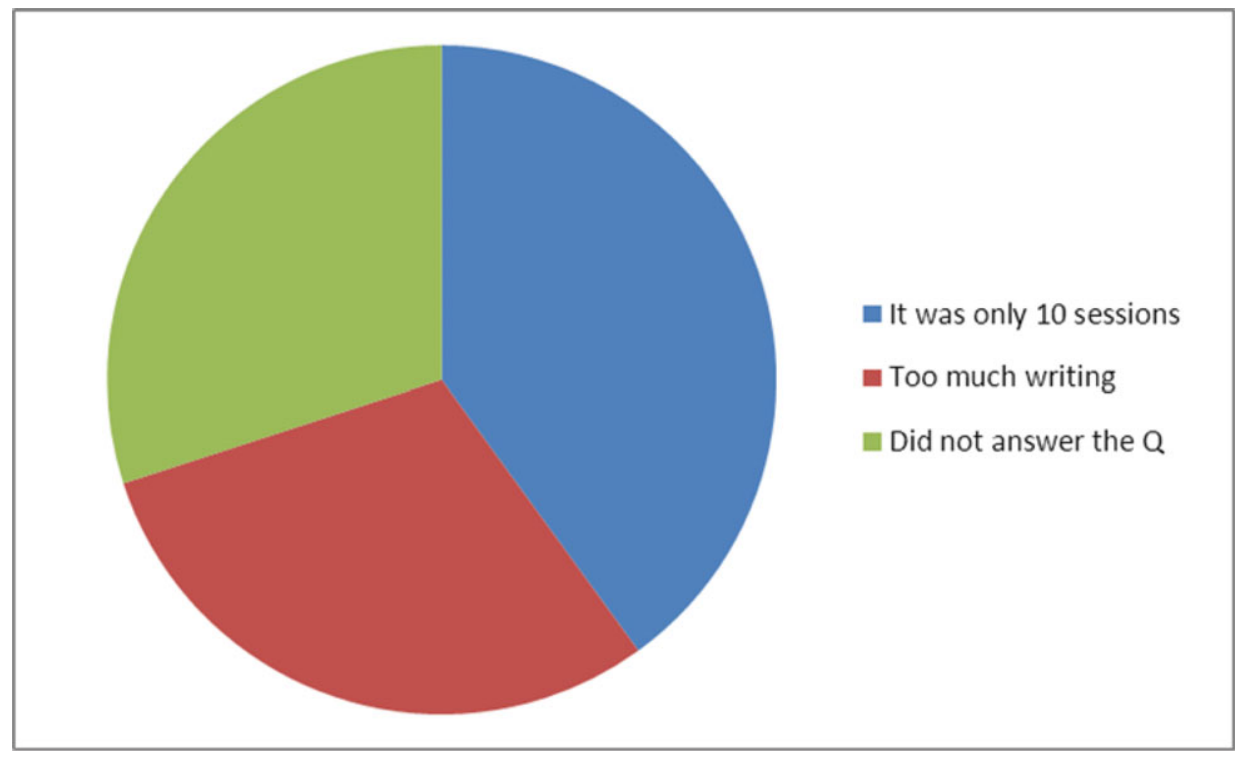

\section{Figure 2}

(Colour online) What did the participants enjoy the least? 


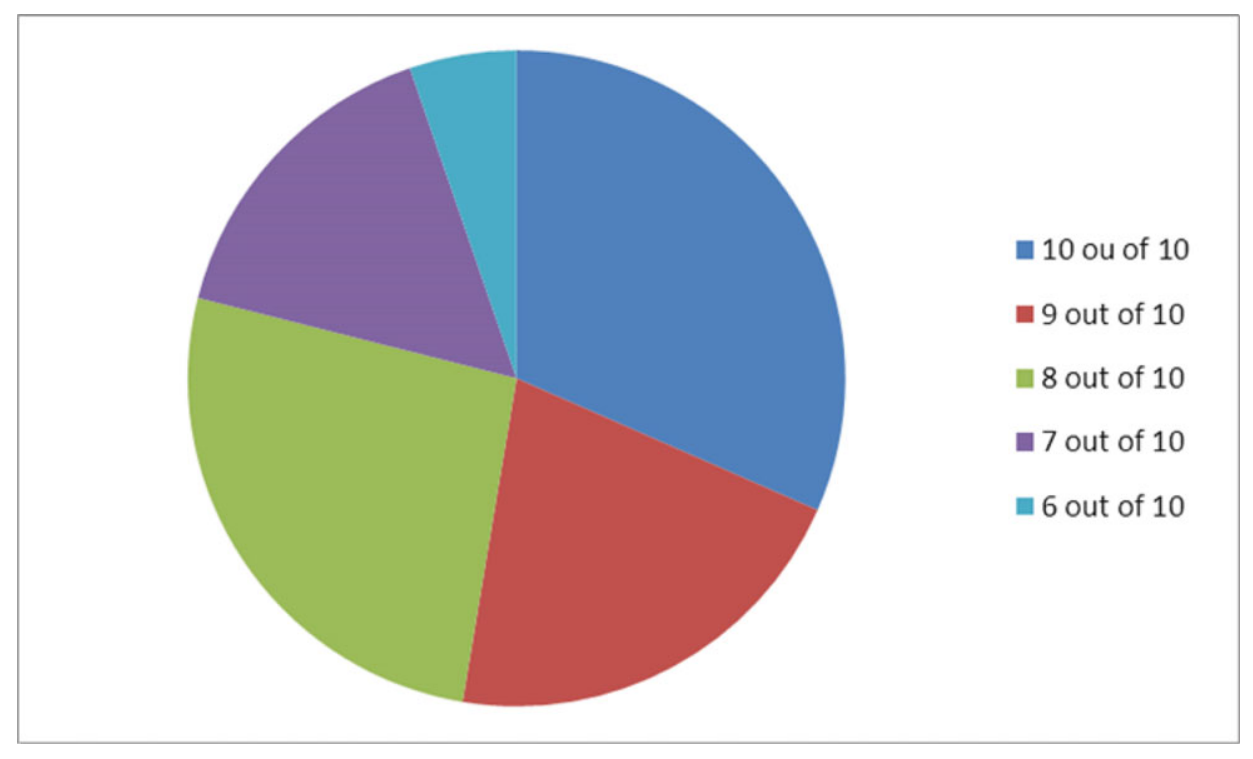

\section{Figure 3}

(Colour online) How did the children rate the program?

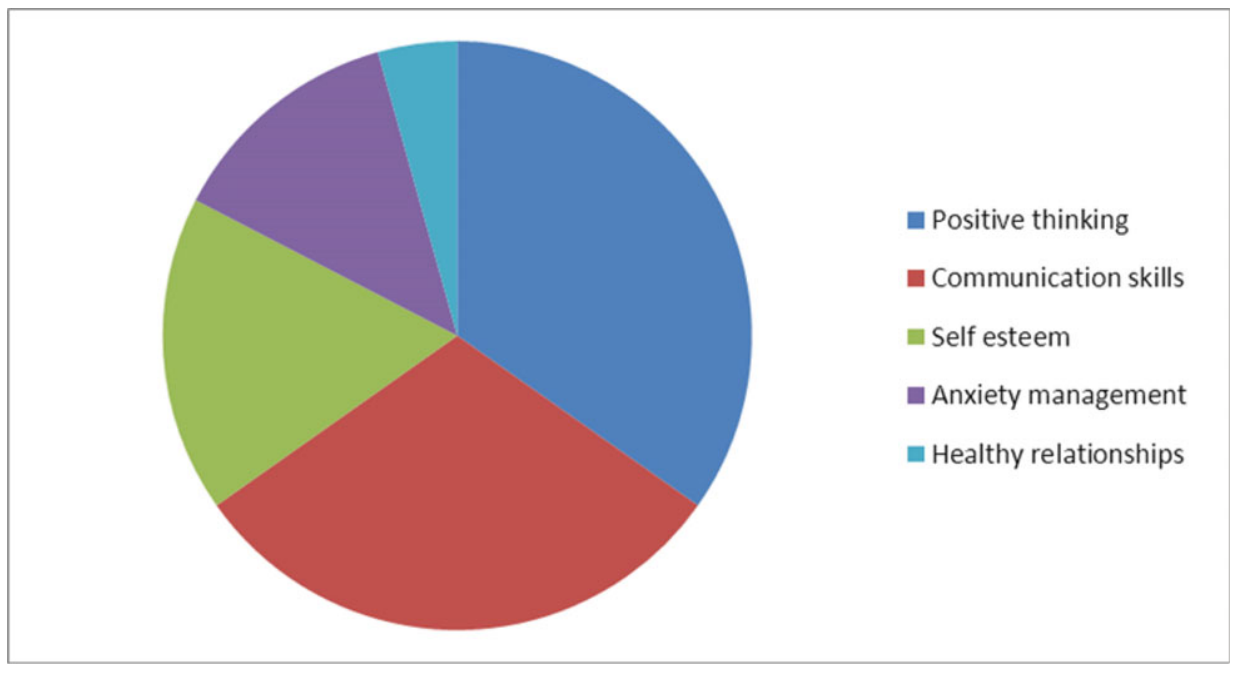

Figure 4

(Colour online) What modules were best received by your children?

In response to how parents may have observed a change in their children after participation in the Healthy Mindsets for Super Kids program (question 4), parents made the following statements: 


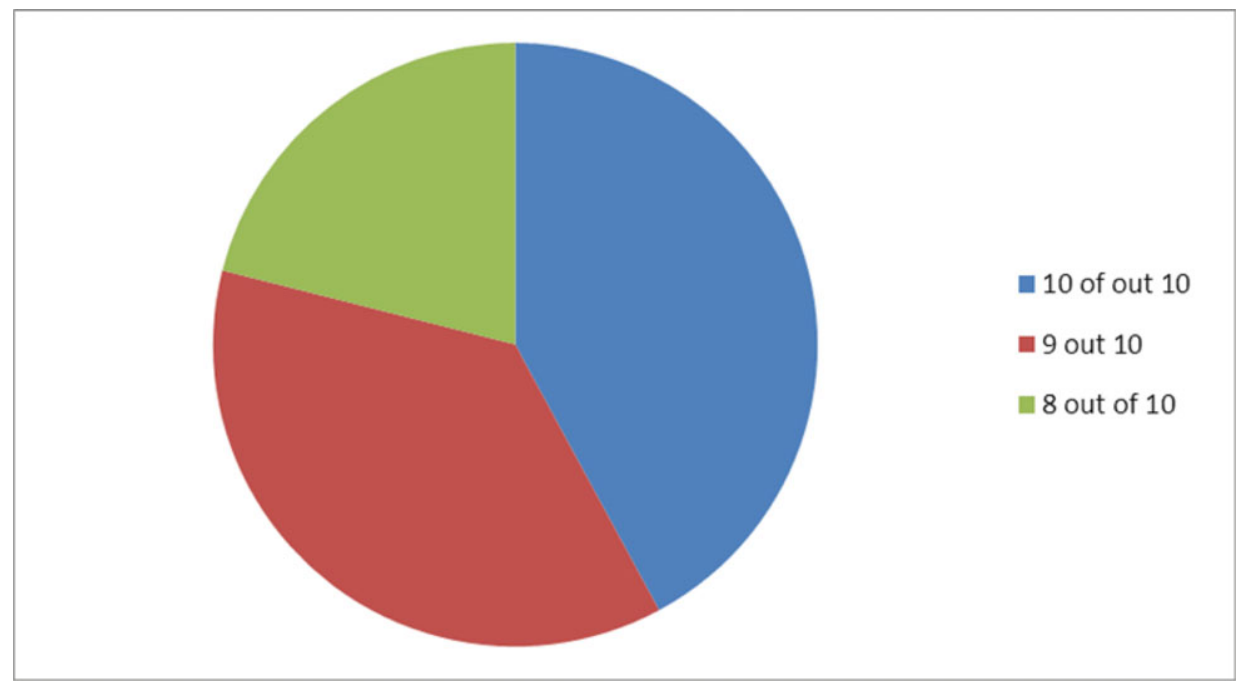

\section{Figure 5}

(Colour online) How did parents rate the program?

My daughter is feeling more confident about high school now. We haven't had tears for a while when talking about it. This is definitely a change.

I would say the course has opened a dialogue between family members. We now just discuss things using some of the skills be learnt and it has improved the dynamics, simply because he doesn't feel threatened anymore.

He does not overreact as much.

He's been trying to manage his anger. He's still got issues with it, but it's the first time I see my son actually trying!

She's been more affectionate. She'll just let me sit with her and hug her while we talk. It never used to happen.

The final question invited parents of participants to rate the utility of the program (see Figure 5). All parents who participated in the evaluation process identified a final rating.

\section{Facilitator Data}

The facilitators' responses were recorded through the use of a facilitator's diary/journal completed at the conclusion of each module and at the end of the program. The summary of key themes drawn from the facilitator data is presented below:

The modules were clear and easy to follow. I had no issues in following the instructions.

Children responded well when the hands-on activity was directly linked to lesson. I think that the hands-on part was vital. 
First time a program covered all the children's needs in one go.

I would probably advise that it would be best to keep children in similar age groups.

Brilliant psychosocial outcomes. Subtle changes were almost immediate.

Highly recommended.

The anger management, self-esteem and communication modules were the most popular. Most likely due to the hands-on activities which the kids just loved.

\section{Discussion}

This evaluation of the Healthy Mindsets for Super Kids program occurred over 2 years and two sites. Thirty-six children and 22 parents participated in this trial. While the results were very positive about the efficacy of the program, the evaluation displayed strengths, weaknesses and discussion points worth addressing below.

\section{Strengths}

The 36 children who participated in the Australian trial described the Healthy Mindsets for Super Kids program as an enjoyable and engaging program. The two facilitators involved in running the sessions commented on the utility of the program, emphasising its sound clinical base and its user-friendly resources. Based on parent feedback, the program demonstrated high utility in its capacity to encourage the development of resilience in children drawn from universal community populations. Further, evaluation data demonstrated the program's benefits for children aged 9-14 years. The positive feedback from family, teachers, and social workers who facilitated the trial demonstrated the program's capacity to be utilised by a range of professionals, including social workers in private practice, teachers and guidance officers in school settings, and community-based groups drawn from a range of community contexts.

\section{Limitations}

This evaluation demonstrated some limitations that need to be acknowledged in this article. First, the evaluation consisted of a limited number of trials. Only two sites participated in the evaluation, which included a fairly small number of participants overall. Second, the evaluation only considered the short-term changes and experiences of children, families and facilitators. An evaluation considering the children's progress after 6 months (or 1 year) post-participation would have allowed for a more significant set of results. Finally, the lack of funding and resources impacted on the ability of this program to be facilitated and evaluated with more children and throughout different sites. Although the program was available online for AUD\$35, the resources and other costs could total AUD\$250 for each intake.

\section{Recommendations}

Following the evaluation of the Healthy Mindsets for Super Kids, a number of recommendations can be made that serve to inform practitioners in the provision of preventative programs for children. First, programs that consider the improvement of existing strengths in children, rather than focusing on the 'pathology' of 
particular behaviours, should be encouraged (Larmar, 2008). Second, the teaching of resilience skills should be facilitated over time, in a consistent manner, and adapted to children's individual needs. This approach serves to reinforce learning and encourage ongoing skills acquisition. Further, practitioners should consider the barriers that prevent children to access such support (Australian Research Alliance for Children and Youth, 2012; Larmar, 2008; Nair, 2012). Such consideration would serve to highlight strategies to widen participation as a means of making preventative programs more accessible for a range of community populations. Additionally, social workers and other allied health practitioners should advocate for programs to be routinely available to parents, teachers, and other allied health clinicians in local communities and at costs that are sustainable for regular community groups. Finally, based on the evaluations undertaken, Healthy Mindsets for Super Kids was found to be an efficient and practical resource suitable for professionals in the education, clinical and community sector.

\section{Conclusions}

This article provided an overview of the Healthy Mindsets for Super Kids, a newly published program by Jessica Kingsley Publishers. The program was designed to target children drawn from universal community populations who may benefit from ongoing resilience training as a preventative measure. The content of the program was outlined and a brief overview of its structure and methods were delineated. Further, a summary of the program's evaluation was presented, highlighting the positive changes experienced by child and parent participants in terms of the children's general wellbeing and emotional health. Finally, recommendations were considered that emphasise the need for resilience programs to be available to clinicians and children across various contexts as a means of enabling children from a range of contexts to have equal access to resilience-building skills programs.

\section{References}

Australian Research Alliance for Children and Youth (ARACY). (2012). A national plan for child and youth wellbeing: A review of the literature. Canberra, Australia: KPMG.

Creswell, J. (2009). Research design. London, UK: Sage.

Creswell, J. (2003). Research design: Qualitative, quantitative, and mixed methods approaches. Thousand Oaks, CA: Sage.

Daniel, B., \& Wassell, S. (2002). The school years: Assessing and promoting resilience in vulnerable children. London, UK: Jessica Kingsley.

Hunter, C. (2012). Is resilience still a useful concept when working with children and young people? Melbourne, Australia: Australian Institute of Family Studies.

Larmar, S. (2008). The early impact program: Strengthening child competencies. Australian Journal of Guidance and Counselling, 18, 128-140.

Leadbeater, B., Dodgen, D., \& Solarz, A. (2005). The resilience revolution: A paradigm shift for research and policy. In R.D. Peters, B. Leadbeater, \& R.J. McMahon (Eds.), Resilience in children, families, and communities: Linking context to practice and policy (pp. 47-63). New York, NY: Kluwer Academic Press. 
Masten, A., Best, K., \& Garmezy, N. (1990). Resilience and development: Contributions from the study of children who overcome adversity. Development and Psychopathology, 2(4), 425-444.

Masten, A. (1999). Resilience comes of age: Reflections on the past and outlook for the next generation of research. In M.D. Glantz \& J.L. Johnson (Eds.), Resilience and development: Positive life adaptations, pp. 281-296. New York, NY: Kluwer Academic Press.

Ministerial Council on Education, Employment, Training and Youth Affairs (MCEETYA). (2008). Melbourne Declaration on Educational Goals for Young Australians. Retrieved April 14, 2013, from http://www.mceecdya.edu.au/verve/_ resources/national_declaration_on_the_educational_goals_for_young_ australians.pdf

Mukherji, P., \& Albon, D. (2010). Research methods in early childhood. London, UK: Sage.

Nair, L. (2012). Safe and supportive families and communities for children. A synopsis and critique of Australian research (CFCA Paper No. 1). Melbourne, Australia: Australian Institute of Family Studies. Retrieved May 27, 2013, from http://www.aifs.gov.au/cfca/pubs/papers/01/cfca01.pdf

National Children's Home (NCH). (2007). Literature review: Resilience in children and young people. London, UK: NCH The Children's Charity.

Werner, K. (1993). Risk, resilience and recover: Perspectives from the Kauai longitudinal study. Development and Psychopathology, 5, 503-515. 